Journal of

Molecular Microbiology

and Biotechnology
J Mol Microbiol Biotechnol 2018;28:87-97

DOI: $10.1159 / 000489929$
Received: February 20, 2018 Accepted: May 5, 2018 Published online: July 11, 2018

\title{
The Extended C-Terminal a-Helix of the HypC Chaperone Restricts Recognition of Large Subunit Precursors by the Hyp-Scaffold Machinery during [NiFe]-Hydrogenase Maturation in Escherichia coli
}

\author{
Claudia Thomas Mandy Waclawek Kerstin Nutschan Constanze Pinske \\ R. Gary Sawers \\ Institute for Biology/ Microbiology, Martin-Luther University Halle-Wittenberg, Halle (Saale), Germany
}

\section{Keywords}

HypC chaperone $\cdot$ HybG · Apo-enzyme recognition · [NiFe]hydrogenase $\cdot$ Metalloenzyme maturation $\cdot \mathrm{H}_{2}$ production $\cdot$ $\mathrm{H}_{2}$ oxidation

\begin{abstract}
Members of the HypC protein family are chaperone-like proteins that play a central role in the maturation of [NiFe]-hydrogenases (Hyd). Escherichia coli has a second copy of HypC, called HybG, and, as a component of the HypDEF maturation scaffold, these proteins help synthesize the NiFe-cofactor and guide the scaffold to its designated hydrogenase large subunit precursor. HypC is required to synthesize active Hyd1 and Hyd-3, while HybG facilitates Hyd-2 and Hyd-1 synthesis. To identify determinants on HypC that allow it to discriminate against Hyd-2, we made amino acid exchanges in 3 variable regions, termed VR1, VR2, and VR3, of HypC, that make it more similar to HybG. Region VR3 includes a HypCspecific C-terminal a-helical extension, and this proved particularly important in preventing the maturation of $\mathrm{Hyd}-2$ by HypC. Truncation of this extension on HypC increased Hyd-2 activity in the absence of $\mathrm{HybG}$, while retaining maturation of Hyd-3 and Hyd-1. Combining this truncation with amino
\end{abstract}

\section{KARGER}

(c) 2018 S. Karger AG, Basel

E-Mail karger@karger.com

www.karger.com $/ \mathrm{mmb}$ acid exchanges in VR1 and VR2 of HypC negatively affected the synthesis of active Hyd-1. The C-terminus of E. coli HypC is thus a key determinant in hindering Hyd-2 maturation, while VR1 and VR2 appear more important for Hyd-1 maturation.

c) 2018 S. Karger AG, Basel

\section{Introduction}

Hydrogen $\left(\mathrm{H}_{2}\right)$ is an important source of reductant for many bacteria and archaea living in anaerobic environments. The ability to evolve $\mathrm{H}_{2}$ also allows many fermentatively growing microorganisms to achieve redox balance. The harnessing of these processes, $\mathrm{H}_{2}$ oxidation and proton reduction, in effective and controlled ways has great potential for alternative energy conversion. Consequently, understanding how [NiFe]-hydrogenases, which catalyze the reversible activation of $\mathrm{H}_{2}$, are assembled and how they function are important goals of current research. [NiFe]-hydrogenases (Hyd) are found in both archaea and bacteria [Vignais and Billoud, 2007], and the core enzyme is composed of large and small subunits. The catalytically active large subunit harbors the active site 
$\mathrm{NiFe}(\mathrm{CN})_{2} \mathrm{CO}$-cofactor, while the small subunit contains iron-sulphur clusters (FeS) that help transfer electrons to and from the bimetallic cofactor, depending on whether the enzyme has a bias towards oxidizing $\mathrm{H}_{2}$ or proton reduction. In bacteria like Escherichia coli, Hyd enzymes are anchored to the membrane by a further subunit, or subunits [Adams and Hall, 1979; Ballantine and Boxer, 1985; Sawers et al., 1985], and these provide a means of electrical contact with the quinone pool and other respiratory complexes [Pinske and Sawers, 2016].

Many anaerobic and facultatively anaerobic archaea and bacteria synthesize more than $1 \mathrm{Hyd}$, and these enzymes must be made and assembled at appropriate stages of growth or under particular growth conditions. E. coli is able to synthesize 3 Hyd enzymes, whereby the first 2 are dedicated to $\mathrm{H}_{2}$ oxidation while the third produces $\mathrm{H}_{2}$. Synthesis of these enzymes is controlled on several levels, including transcription, translation, as well as cofactor biosynthesis, enzyme assembly, and membrane targeting [Böck et al., 2006; Penfold et al., 2006], which respond in turn to the physiological status of the cell and whether sufficient resources, such as metal ions and metabolites required for biosynthesis, are available. Although much is understood for several bacteria concerning transcriptional control of the genes and operons encoding Hyd and, to a certain extent, enzyme assembly [Böck et al., 2006; Pinske and Sawers, 2016], there is still much we do not understand about how such processes are controlled and coordinated. In particular, post-translational synthesis, assembly, and insertion of metal cofactors determines when a particular Hyd is active [Lacasse and Zamble, 2016; Pinske and Sawers, 2016; Sargent, 2016], and although in-roads have been made in this research direction, this area is still poorly understood.

Synthesis and insertion of the $\mathrm{NiFe}(\mathrm{CN})_{2} \mathrm{CO}$ cofactor into the precursor of the Hyd large subunit is considered a two-step process requiring, minimally, 6 Hyp proteins, which are conserved in all microorganisms that synthesize [NiFe]-Hyd [Jacobi et al., 1992; Jones et al, 2004; Böck et al., 2006]. Some of these proteins have further enzyme-specific copies, like the HypF proteins in Alcaligenes eutrophus [Wolf et al., 1998]. E. coli has a para£logue of HypC, called HybG, that is encoded within the hybOABCDEFG operon [Menon et al., 1994]. HybG has been shown to be required for the maturation of $\mathrm{HybC}$, the large subunit of the Hyd-2 enzyme, which is encoded in the same operon as HybG [Blokesch et al., 2001]. In contrast, the maturation of $\mathrm{HycE}$, the large subunit of the hydrogen-producing Hyd-3, depends solely on HypC [Magalon and Böck, 2000; Blokesch et al., 2004]. More- over, although $\mathrm{HybG}$ is mainly required for Hyd-1 activity, $\mathrm{HypC}$ is also capable of maturing $\mathrm{HyaB}$, the large subunit of Hyd-1, in a mutant lacking HybG [Blokesch et al., 2001].

The HypC chaperone was originally identified to interact with the precursor form of $\mathrm{HycE}$, the large subunit of Hyd-3 in E. coli [Drapal and Böck, 1998; Magalon and Böck, 2000]. Subsequently, HypC was shown to form a tight complex with HypD [Blokesch et al., 2004] and the HypCD complex, which was crystallized from Thermococcus kodakarensis, also associates with $\mathrm{HypE}$ and $\mathrm{HypF}$ [Bürstel et al., 2012; Watanabe et al., 2012; Stripp et al., 2013; Senger et al., 2017].

The HypDEF proteins are universally required for all 3 Hyd in E. coli and, together with the HypC/HybG protein, they perform the first part of the maturation reaction. The iron ion is liganded with $1 \mathrm{CO}$ and $2 \mathrm{CN}^{-}$ groups, and synthesis of this $\mathrm{Fe}(\mathrm{CN})_{2} \mathrm{CO}$ moiety is completed on a HypCDEF- or HypDEF-HybG-scaffold complex [Bürstel et al., 2012; Stripp et al., 2013]. This modified group is subsequently inserted into the open active site cavity of the large subunit. There is, meanwhile, strong evidence to indicate that the apo-form of the Hyd large subunit adopts a conformation that facilitates complex recognition and cofactor insertion [Drapal and Böck, 1998; Magalon and Böck, 2000; Jones et al., 2004; Winter et al., 2005].

Members of the HypC-family are small, approximately $10-\mathrm{kDa}$ proteins that share a common OB- $\beta$-fold [Wang et al., 2007]. They also have a highly conserved and essential cysteinyl residue at amino acid position 2 on the polypeptide chain [Blokesch et al., 2004]. The N-terminal methionyl residue is removed from the final protein product, and Cys-2 is assumed to coordinate the $\mathrm{Fe}(\mathrm{CN})_{2} \mathrm{CO}$ moiety, together with the thiol of the essential Cys-41 (E. coli nomenclature) of HypD [Blokesch and Böck, 2006; Bürstel, et al., 2012; Soboh et al., 2012; Stripp et al., 2013]. This indicates that HypC is an intermediary between the Hyp-scaffold and the large subunit precursors. Due to the dual coordination of the $\mathrm{Fe}(\mathrm{CN})_{2} \mathrm{CO}$ moiety by HypC/HybG and HypD, it is likely that the HypC/HybG proteins transfer the $\mathrm{Fe}(\mathrm{CN})_{2} \mathrm{CO}$ to their respective large subunits without completely detaching from HypD, in order to protect the cofactor. It is currently unclear, however, whether HypC or HybG is responsible for cofactor insertion into the large subunit of Hyd-4 in E. coli [Pinske and Sawers, 2016].

Nickel is introduced by the HypAB and SlyD proteins after insertion of $\mathrm{Fe}(\mathrm{CN})_{2} \mathrm{CO}$ has taken place [Böck et al., 2006; Lacasse and Zamble, 2016]. Apart from nickel-in-
88

J Mol Microbiol Biotechnol 2018;28:87-97 DOI: $10.1159 / 000489929$
Thomas/Waclawek/Nutschan/Pinske/ Sawers 
serting HypA and its paralogue HybF, the 2 HypC paralogues are the only Hyp proteins in E. coli that are duplicated and that have hydrogenase-specific functions. This indicates that it is these proteins, possibly together with HypD in the Hyp-scaffold complex, which are responsible for guiding the complex to a particular Hyd large subunit precursor and completing $\mathrm{Fe}(\mathrm{CN})_{2} \mathrm{CO}$ group insertion. Nevertheless, little is known about how the scaffold complex recognizes individual hydrogenase large subunits, but based on the above considerations, it is conceivable that the HypC and HybG proteins have a key role in discriminating the large subunit precursors.

A recent study identified 3 variable regions in the HypC and HybG proteins that could potentially be involved in the recognition of the Hyd large subunit precursor [Hartwig et al., 2015]. Amino acid residues in these variable regions of HybG that conferred upon it the ability to mature Hyd-3, at least partially, could be identified [Hartwig et al., 2015]. In this study, we have undertaken a detailed analysis of these 3 variable regions in HypC and analyzed their influence on the protein's ability to distinguish between the precursors of the large subunits of Hyd-1 (HyaB), Hyd-2 (HybC), and Hyd-3 (HycE). Our findings demonstrate that the extended $\mathrm{C}$-terminal helix of HypC is decisive in restricting HypC to mature the Hyd-3 and Hyd-1 enzymes.

\section{Results}

\section{Competition between Hydrogenase Precursors for}

$\mathrm{HypC}$ and $\mathrm{HybG}$

A strain carrying a deletion in the hypC gene no longer synthesized active Hyd-3 but retained active Hyd-1 and Hyd-2 (Fig. 1a). While Hyd-2 activity was comparable to that in the wild-type strain MC4100, Hyd-1 activity was reduced, verifying a role for HypC in Hyd-1 maturation [Blokesch et al., 2001]. Surprisingly, although the introduction of multicopy hypC into the hypC mutant partially recovered Hyd-3 activity, it abolished detectable Hyd-2 enzyme activity (Fig. 1a). Moreover, while the activity of Hyd-1 was further reduced compared to the hypC mutant, use of the more sensitive $\mathrm{H}_{2}$ :nitroblue-tetrazolium (NBT) activity stain [Pinske et al., 2012] nevertheless revealed that residual Hyd-1 activity was still present (Fig. 1b). Introduction of a plasmid encoding $\mathrm{HybG}^{\text {Strep }}$ into the hypC mutant reduced Hyd-3 activity still further (Fig. 1a), but Hyd-1 activity remained at a similar level to that observed when multicopy HypC was introduced into the hypC mutant (Fig. 1b). It should be noted that per-

HypC Recognition of Hydrogenase

Apo-Large Subunits

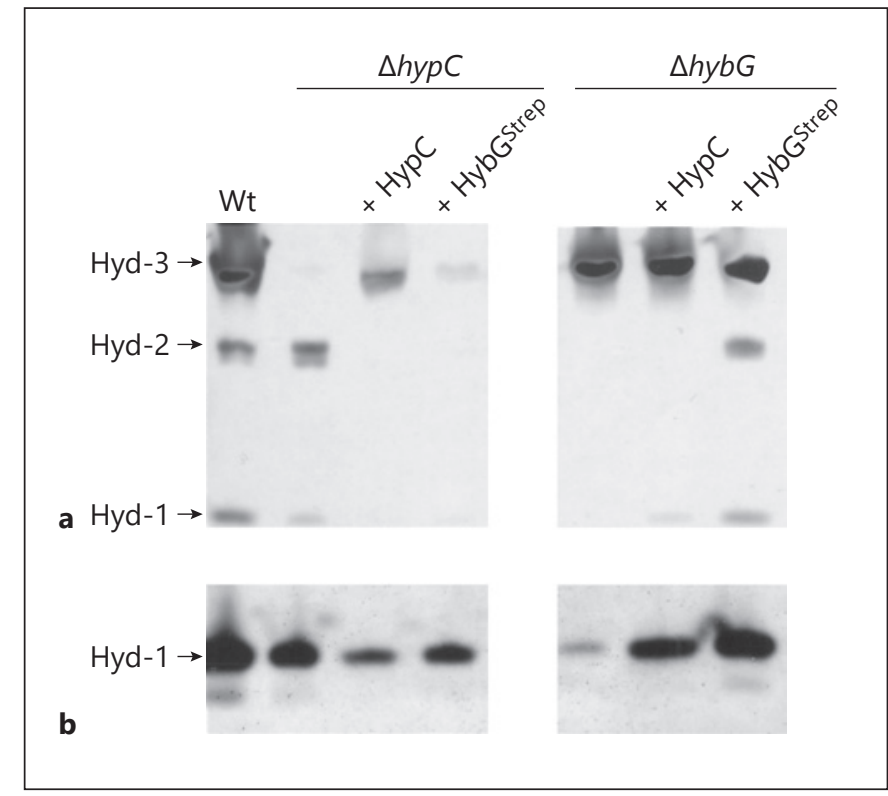

Fig. 1. Multicopy hypC out-competes HybG to mature Hyd-3 preferentially. Non-denaturing PAGE analysis of crude extracts $(50 \mu \mathrm{g}$ of protein) derived from the strains MC4100 (Wt), DHP-C $(\triangle h y p C)$ and DHP-G $(\Delta h y b G)$ grown in M9 minimal medium with glucose as a carbon source. Strain DHP-C was analyzed with and without pJA1021 (hypC) and DHP-G was also analyzed after transformation with pJA1021 or phybGstrep $(h y b G)$. Note that while HypC encoded on pJA1021 carries no tag, HybG carries a $\mathrm{N}$-terminal Strep-tag. After electrophoresis, the gels were stained for Hyd activity with BV-TTC (a) or PMS-NBT (b) in an atmosphere of $100 \% \mathrm{H}_{2}$ (see Experimental procedures for details). The migration positions of Hyd-1, Hyd-2, and Hyd-3 are shown on the left of the gel.

forming the same experiment with a plasmid encoding HybG without a Strep-tag gave a similar result (data not shown), indicating that the tag was not responsible for the reduction in hydrogenase enzyme activity. These results clearly demonstrated that increasing the gene-dosage of either $h y p C$ or of $h y b G$ strongly interfered with the synthesis of the remaining Hyd, presumably through competition for $\mathrm{Fe}(\mathrm{CN})_{2} \mathrm{CO}$. The copy number of pACYC184based plasmids with a p15A ori is around 10-15 copies per cell, while plasmids with a f1 origin (pASK-IBA) have copy numbers in the range of $>100$ per cell.

In a reciprocal set of experiments, we examined the effect of deleting the $h y b G$ gene on the Hyd enzyme profile. A $h y b G$ allele had no detrimental effect on the activity of Hyd-3, but abolished Hyd-2 activity and strongly reduced Hyd-1 activity (Fig. 1a, b). This finding confirms the role of $\mathrm{HybG}$ in the recognition and maturation of $\mathrm{HyaB}$, the catalytic large subunit of Hyd-1 [Blokesch et al., 2001]. 


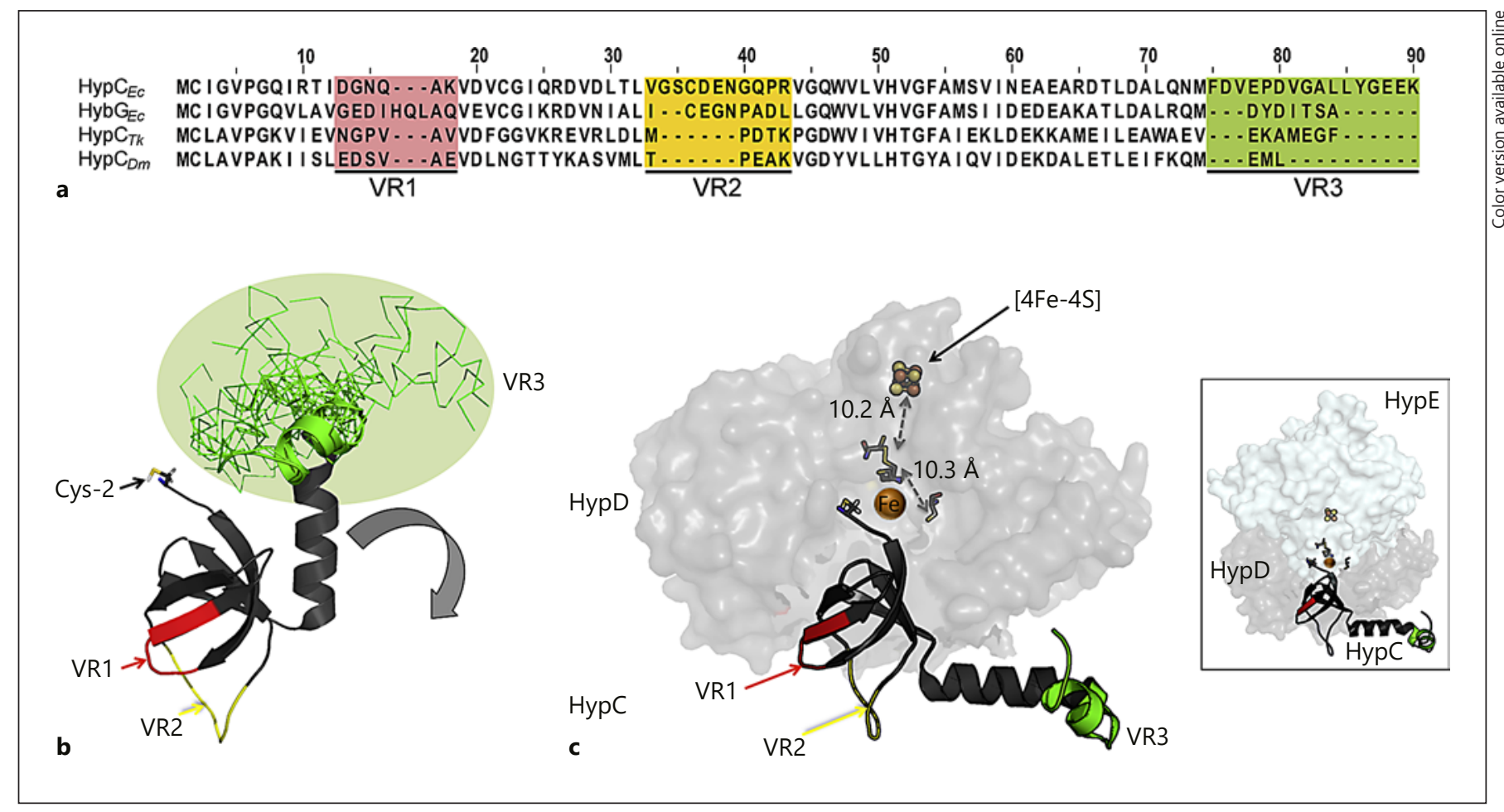

Fig. 2. Structural representation of the HypC protein and its orientation in the Hyp-scaffold complex. a Alignment of selected HypC family members. HypC $\mathrm{E}_{\mathrm{c}}$, HypC from E. coli; $\mathrm{HybG}_{\mathrm{Ec}}$, HybG from E. coli; $\mathrm{HypC}_{\mathrm{Tk}}$, HypC from T. kodakarensis; $\mathrm{HypC}_{\mathrm{Dm}}$, HypC from D. mccartyi strain CBDB1. Amino acid sequence is shown in single-letter code and the variable regions VR1, VR2, and VR3 are highlighted in red, yellow, and green, respectively. b Shown is a cartoon view of the NMR solution structure of HypC from E. coli [Wang et al., 2007] (PDB 2OT2). The locations of the variable regions VR1, VR2, and VR3 are indicated. All states of the structure are shown simultaneously as ribbons for the VR3 region. The catalytically important Cys-2 has a stick representation, and

Introduction of additional copies of the hypC gene into the $h y b G$ mutant did not affect Hyd-3 activity, nor did they restore Hyd-2 activity, but they did augment Hyd-1 activity (Fig. 1). In contrast, introduction of the hybG gene restored Hyd-2 enzyme activity to wild-type levels, increasing Hyd-1 activity further, compared to when hypC was introduced (Fig. 1b), but reducing Hyd-3 enzyme activity (Fig. 1a). Together, these results suggest that: (1) the HypC and HybG proteins compete for the HypDEF-scaffold complexes; (2) in the absence of HypC, over-production of $\mathrm{HybG}$ causes reduction of $\mathrm{Hyd}-3$ and Hyd-2 maturation; and (3) the resulting HypC/HybGDEF complexes might also compete for hydrogenase large subunit precursors. an arrow indicates the predicted movement of the a-helix upon binding to HypD. c A representation of the structure of the HypCHypD complex from T. kodakarensis [Watanabe et al., 2012] (PDB 3VYR), but with $\mathrm{HypC}_{\mathrm{Tk}}$ replaced by the $E$. coli solution structure (PDB 2OT2). HypD (a gray surface model) with its [4Fe-4S]-cluster (depicted as spheres), the distance to the bridging, and the catalytic Cys residues (shown as sticks). The concerted binding of the iron moiety is indicated as an Fe-sphere and the locations of the VR1, VR2, and VR3 regions of HypC by colors and arrows (as in a; online supplementary Figure S1). Inset The same structural model, but with the location of HypE appearing as a light blue surface structure (based on PDB 3VYU).

\section{HypC Determinants Important for the Recognition of $H y c E$}

Alignment of the amino acid sequences of HypC and HybG from E. coli, together with the crystallized protein orthologues of HypC from T. kodakarensis and the previously described HypC from the Dehalococcoides mccartyi strain CBDB1 (Fig. 2a), highlights the 3 variable regions, VR1 (amino acids 13-18 with reference to $\mathrm{HypC}_{\mathrm{Ec}}$ ), VR2 (33-43), and VR3 (75-90); the amino acid range of VR1 and of VR3 has been restricted somewhat compared to the previous definition [Hartwig et al., 2015]. The solution structure of HypC from $E$. coli has been determined [Wang et al., 2007] and the locations of VR1, VR2, and VR3 in the protein are shown in Fig. 2b. However, based
90

J Mol Microbiol Biotechnol 2018;28:87-97 DOI: $10.1159 / 000489929$
Thomas/Waclawek/Nutschan/Pinske/ Sawers 


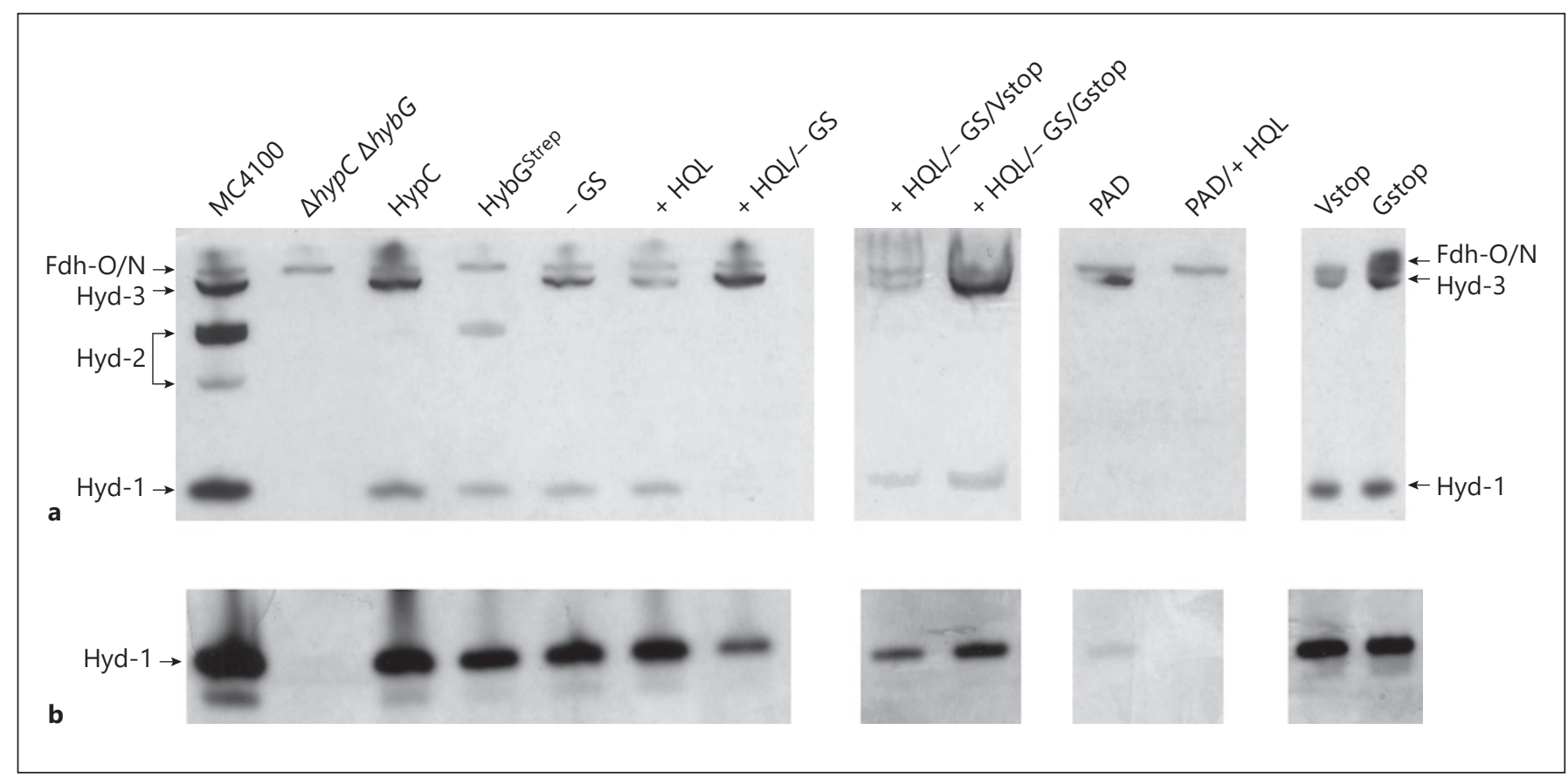

Fig. 3. Influence of amino acid changes in the variable regions of HypC on the Hyd enzyme activity profile. Proteins of crude extracts (50 $\mu \mathrm{g}$ of protein), derived from the indicated strains after anaerobic growth in M9 minimal medium with glucose as a carbon source, were separated by non-denaturing PAGE (6\% w/v polyacrylamide), and subsequently stained for hydrogenase enzyme activity using either BV-TTC (a) or PMS-NBT (b) (see Experimental Procedures for details). The enzymes responsible for the respective activity bands are shown on the left of the gel images. The activity-staining band labelled Fdh-O/N signifies the weak $\mathrm{H}_{2}$-oxidizing activity associated with the formate dehydrogenases $\mathrm{O}$ and $\mathrm{N}$ [Soboh et al., 20011] (and acted as a loading control). With the exception of the wild-type MC4100, all other samples were derivatives of strain $\mathrm{SHH} 228(\Delta h y p C \Delta h y b G)$ transformed with plasmids (Table 2) encoding the indicated HypC variants. on the co-crystal structure of the HypC-HypD complex from T. kodakarensis [Watanabe et al., 2012], the amino acids in these variable regions are clearly not involved in the interaction with HypD, and they align along an axis on the opposite side to the HypC-HypD interaction surface (Fig. 2c). Therefore, in order to analyze their potential role in $\mathrm{HypC}$ recognition of the large-subunit precursors, we decided to make HypC more similar to its paralogue $\mathrm{HybG}$ by introducing a series of changes in which different amino acids were added or removed (online suppl. Fig. S1; for all online suppl. material, see www. karger.com/doi/10.1159/000489929). Some of these exchanges were combined to create derivatives with multiple changes in VR1, VR2, and VR3. The changes made in VR1 included the introduction of the HQL tripeptide between amino acids 15 and 16, which is present in HybG but normally absent from HypC, creating HypC (+ HQL). A further amino acid exchange in region VR1 included converting a glycyl residue at position 14 in $\mathrm{HypC}$ to an aspartyl residue found in $\mathrm{HypC}_{\mathrm{Dm}}$ (Fig. 2a), generating
HypC(G14D). Changes introduced in region VR2 included the deletion of the GS dipeptide (positions 34 and $35)$ to create $\mathrm{HypC}(-\mathrm{GS})$ and the GQP tripeptide at positions 40-42 was exchanged for PAD to deliver HypC(PAD). In VR3, 2 C-terminally truncated variants, HypC(Gstop) and HypC(Vstop), which removed 9 and 14 amino acids, respectively, from the C-terminus, were constructed to deliver proteins of a length similar to HybG (82 amino acids) and HypC (71 amino acids) from D. mccartyi, respectively.

Genes encoding these variants were introduced into the $\Delta h y p C-\Delta h y b G$ double null mutant, SHH228 [Hartwig et al., 2015], and after anaerobic fermentative growth in glucose minimal medium, Hyd-containing protein complexes in detergent-solubilized crude extracts derived from these strains were separated in non-denaturing polyacrylamide gel electrophoresis (PAGE), and subsequently stained for $\mathrm{H}_{2}$-oxidizing enzyme activity (Fig. 3a). As a control, introduction of the wild-type hypC gene restored Hyd-3 and partially restored Hyd-1 activity bands, 
Table 1. Formate hydrogenase enzyme activity of E. coli SHH228 (hypC hybG) transformed with plasmid-encoded HypC amino acid variants

\begin{tabular}{lc}
\hline Strain & $\begin{array}{l}\text { Relative formate } \\
\text { dehydrogenase } \\
\text { activity }\end{array}$ \\
\hline MC4100 & $1.63 \pm 0.5$ \\
SHH228 (hypC hybG) & $<0.01$ \\
SHH228 + pJA1021 $($ hypC) & $1.07 \pm 0.24$ \\
SHH228 + phybGstrep & $0.08 \pm 0.03$ \\
SHH228 + pCThypC(+ HQL) & $1.42 \pm 0.49$ \\
SHH228 + pCThypC(- GS) & $1.16 \pm 0.17$ \\
SHH228 + pCThypC(+ HQL/- GS) & $1.52 \pm 0.54$ \\
SHH228 + pCThypC(Vstop) & $0.8 \pm 0.02$ \\
SHH228 + pCThypC(Gstop) & $1.13 \pm 0.08$ \\
SHH228 + pCThypC(+ HQL/- GS/Vstop) & $0.14 \pm 0.03$ \\
SHH228 + pCThypC(+ HQL/- GS/Gstop) & $0.51 \pm 0.12$ \\
SHH228 + pCThypC(PAD) & $0.62 \pm 0.02$ \\
SHH228 + pCThypC(PAD/+ HQL) & $<0.01$ \\
SHH228 + pCThypC(PAD/+ HQL/Vstop) & $<0.01$ \\
SHH228 + pCThypC(PAD/+ HQL/Gstop) & $<0.01$ \\
SHH228 + pCThypC(G14D) & $0.7 \pm 0.2$ \\
\hline
\end{tabular}

Data were obtained from at least 3 independent experiments. Formate hydrogenase complex activity is calculated as $\mathrm{nmol} \mathrm{H}_{2}$ $\mathrm{min} / \mathrm{mg}$ and expressed as mean \pm standard error of the mean.

while introduction of the wild-type hybG, encoding Cterminally Strep-tagged HybG, restored weak Hyd-2 and Hyd- 1 activities under these conditions (Fig. 3a, b). Removal of the GS dipeptide from VR2 and introduction of the HQL tripeptide into region VR1 in HypC, both individually and combined, essentially did not impair Hyd-3 enzyme activity. This was also reflected in the ability of these mutated genes to restore effective $\mathrm{H}_{2}$ production to strain SHH228 (Table 1). The combined VR1 and VR2 exchanges did, however, reduce the ability to mature Hyd-1, reflected by a less intense activity band (Fig. 3). The $\mathrm{G}$ to D exchange at position 14 in HypC had no effect on in-gel Hyd-3 activity (not shown), but the change reduced $\mathrm{H}_{2}$ production by approximately $30 \%$ (Table 1 ). Equivalence in the loading of samples was demonstrated by the weak hydrogen-oxidizing activity band due to the formate dehydrogenases Fdh-O and Fdh-N (Fig. 3a) [Soboh et al., 2011].

The C-terminal truncations (VR3 region; online suppl. Fig. S1) also had no strong negative impact on either Hyd-3 enzyme activity of the strain, as revealed by in-gel activity staining (Fig. 3a), or by the measurement of $\mathrm{H}_{2}$ production (Table 1). However, combining the -
GS and + HQL exchanges with the truncation of the Cterminus reduced $\mathrm{H}_{2}$ production by approximately $50 \%$ when the stop codon was introduced at amino acid position 82 (Gstop). Combining the VR1 and VR2 exchanges with the Vstop truncation (introduction of a stop codon at position 76) reduced $\mathrm{H}_{2}$ production to approximately $15 \%$ of the level observed for strain SHH228 complemented with a plasmid encoding native HypC (Table 1). Hyd-3 enzyme activity was also significantly reduced in the HypC(-GS/+ HQL/Vstop) variant. These combined exchanges also all had a significant negative impact on Hyd-1 maturation (Fig. 3b).

To verify the importance of the amino acid sequence in the loop region VR2 for HypC function, the GQP exchange to PAD (as found in HybG) was analyzed. Hyd-3 activity was partially retained when a plasmid encoding a HypC variant carrying these changes was introduced into $\mathrm{SHH} 228$, but $\mathrm{H}_{2}$ production was reduced by approximately 50\% (Fig. 3a; Table 1). Notably, however, Hyd-1 activity was severely impaired and therefore barely detectable when SHH228 was transformed with a plasmid encoding HypC(PAD) (Fig. 3b). Introduction of the HQL amino acids into this construct, and further combining this with truncation of the C-terminus, abolished $\mathrm{H}_{2}$ production (Table 1) as well as Hyd-3 and Hyd-1 enzyme activities (Fig. 3; data not shown). The effects of these changes indicate that key amino acids in this loop/ VR2 region (Fig. 2a) of HypC between $\beta$-sheets 3 and 4 are of particular importance for the interaction with $\mathrm{HycE}$ and/or for maintaining the stability of HypC (see below).

Analysis of the HypC protein levels after over-production by immunoblotting revealed that while the HypC (Gstop) and HypC(+ HQL/- GS/Gstop) variants could readily be detected, including possible dimeric forms of the proteins as observed previously [Soboh et al., 2013; Albareda et al., 2014], the HypC(PAD/+ HQL/Gstop) variant could not be detected (online suppl. Fig. S2). This suggests that the reason the HypC derivatives with the PAD exchange lacked hydrogenase activity, or showed reduced activity, was because they could not be over-produced in a stable form.

Together, the data indicate that the VR1, VR2, and VR3 regions combined play an important role in Hyd-3 maturation; however, only the combined introduction of the HQL sequence, the removal of GS, and the 14-amino acid truncation of the C-terminus strongly reduced Hyd3 activity. Exchange of the GQP amino acid sequence for the PAD tripeptide in VR2 severely affected the protein's stability.
J Mol Microbiol Biotechnol 2018;28:87-97 DOI: $10.1159 / 000489929$
Thomas/Waclawek/Nutschan/Pinske/ Sawers 
Fig. 4. Removal of the extended C-terminal helix of HypC allows it to mature Hyd-2. Proteins of crude extracts ( $50 \mu \mathrm{g}$ of protein) derived from the indicated strains after anaerobic growth in M9 minimal medium with glycerol and fumarate as a carbon source (see Experimental Procedures) were separated by non-denaturing PAGE (6\% w/v polyacrylamide), and subsequently stained for hydrogenase enzyme activity using BV-TTC. The enzymes responsible for the respective activity bands are shown on the left of the gel image. With the exception of the wild-type MC4100, all other samples were derivatives of strain $\mathrm{SHH} 228$ $(\triangle h y p C \triangle h y b G)$ transformed with plasmids (Table 2) encoding the indicated HypC variants.

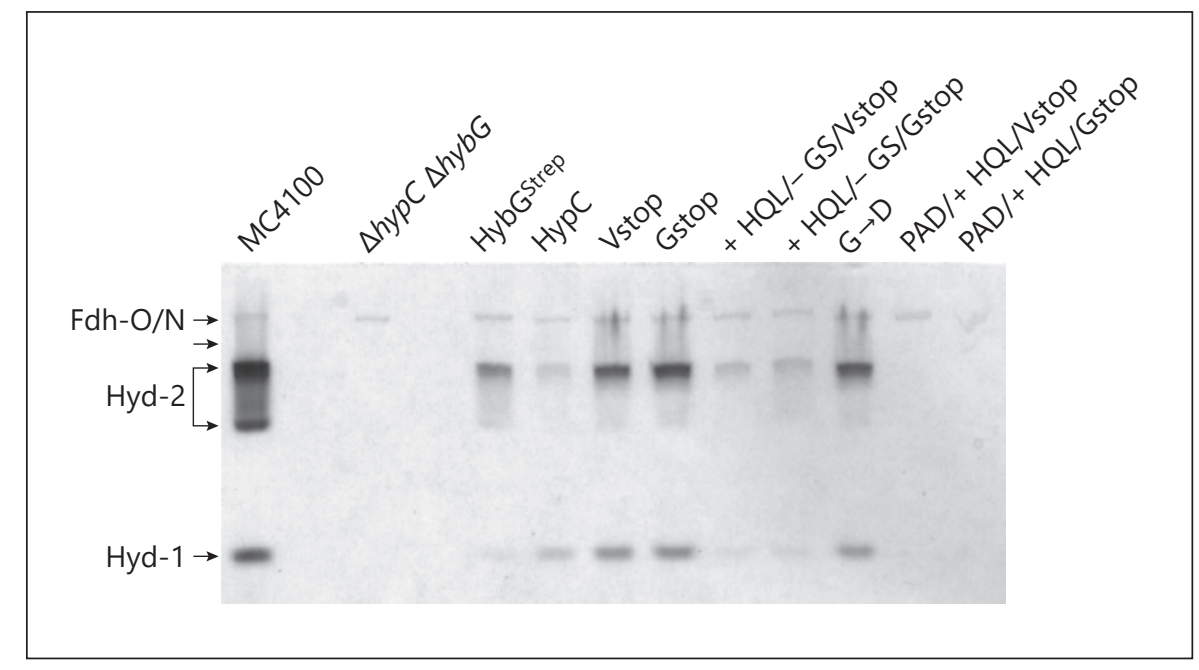

Truncation of the C-Terminal Helix of HypC Improves HybC Maturation

Use of an alternative anaerobic growth condition of $E$. coli with glycerol and fumarate induces high-level synthesis and activity of Hyd-2, while Hyd-3-dependent $\mathrm{H}_{2}$ production is strongly reduced, as is Hyd-1 [Sawers et al., 1985]. Analysis of solubilized crude extracts derived from the strains indicated in Fig. 4 revealed that Strep-tagged, native HybG restored some Hyd-2 activity to strain SHH228 ( $\triangle$ hypC $\Delta h y b G$ ), while native HypC partially recovered Hyd-1 activity and a trace of Hyd-2, possibly as a consequence of multicopy hypC. The weak, anaerobically active Fdh enzymes (labelled Fdh-O/N) acted as loading controls for these experiments. Notably, both HypC variants with C-terminal truncations showed improved Hyd-2 enzyme activity compared with that of native HypC (Fig. 4); Hyd-1 activity was also concomitantly increased. Surprisingly, the HypC(G14D) variant also exhibited a similar increase in Hyd-2 enzyme activity, suggesting this is an important determinant for $\mathrm{HybC}$ recognition. Combining the $\mathrm{C}$-terminal truncations with other changes in VR1 and VR2 led to a similar Hyd-2 activity to that observed for plasmid-encoded native HypC, which is in good agreement with the native-looking Hyd3 and Hyd-1 activity of the former variant in Figure 3. Notably, all hydrogenase activity was abolished when PAD exchanges were combined with changes in VR1 and VR2 (Fig. 4), and this is in accord with an apparent lack of this HypC variant in over-production experiments (online suppl. Fig. S2).

HypC Recognition of Hydrogenase

Apo-Large Subunits

\section{Discussion}

Identifying the key amino acid determinants governing the exclusivity of HypC for the large subunit precursor of Hyd-3 of E. coli was the focus of this study. Our results, as well as those of a previous study [Magalon and Böck, 2000; Blokesch et al., 2001], confirmed that HypC and HybG compete for the Hyp-scaffold complex, because over-production of either reduces the activity of the corresponding target enzyme of the paralogous chaperone; e.g., the introduction of multicopy hypC into a $\triangle h y p C$ mutant prevents appearance of Hyd-2 activity (Fig. 1a). It is notable, however, that introducing multicopy $h y b G$ (up to 100 additional gene copies) into a $\Delta h y b G$ mutant reduced Hyd-3 activity, but did not abolish it, while it restored Hyd-2 (and Hyd-1) activity. However, increasing the copy number of hybG in a hypC mutant by an equivalent amount reduced the Hyd-2 activity. We currently do not fully understand this result, but it suggests that there is a determinant on HybG, that, when the protein is present in multiple copies, either prevents HybG functioning correctly with the Hyp-scaffold complex, or hinders its correct interaction with the hydrogenase large-subunit precursors. Attempts to quantify the levels of HypC and HybG in wild-type cells have so far proved unsuccessful because the lower limit of detection of our antibodies is approximately $10 \mathrm{ng}$ of either purified protein (data not shown). Even loading $50 \mu \mathrm{g}$ of crude extract from a strain carrying multicopy plasmid phybGstrep failed to detect the protein (online suppl. Fig. S3). Assuming, therefore, that HypC or HybG is present at between 0.002 and $0.01 \%$

J Mol Microbiol Biotechnol 2018;28:87-97 DOI: $10.1159 / 000489929$ 
(1-5 $\mathrm{ng}$ in $50 \mu \mathrm{g}$ of soluble extract) of soluble protein, this equates very roughly to only between 50 and $250 \mathrm{nM}$ of these $10-\mathrm{kDa}$ proteins. This low natural abundance of these proteins might explain why an imbalance in $\mathrm{NiFe}$ cofactor [Pinske and Sawers, 2016] distribution occurs when either HypC or HybG is over-produced.

The data nonetheless suggest that HypC takes precedence over HybG regarding its interaction with the HypDEF-scaffold complex, and/or that HypC interacts more efficiently with its target $\mathrm{HycE}$ than does HybG with its principal target HybC. This would also be in accord with the fact that Hyd-3 of the hydrogen-evolving formate hydrogenlyase complex is preferentially made in fermenting E. coli cells [Pinske and Sawers, 2016]. Future studies involving comparing these multicopy effects with the influence of mutated genes in single copy, along with quantitative in vitro chemical cross-linking studies coupled with mass spectrometry analysis with purified proteins, will be required to dissect the precise interactions between these chaperones and their client proteins.

Based partially on these observations, it was decided to introduce the HypC variants into a strain lacking both $h y p C$ and $h y b G$ to obviate competition between the chaperones, which facilitated interpretation of the effects of the amino acid alterations on hydrogenase maturation; the assumption, based on previous studies [Jacobi et al., 1992; Blokesch et al., 2001], was made between the appearance of hydrogenase enzyme activity and maturation of the corresponding large subunit precursor. This proved an effective strategy and allowed us to demonstrate that a key determinant in preventing HypC from maturing HybC (the Hyd-2 large subunit) was the addition of an approximately 8 -amino-acid-long $\alpha$-helix at its C-terminus [Wang et al., 2007] (Fig. 2b). Truncation of the C-terminus to a length similar to that of HybG, or even to that of the shorter HypC protein from D. mccartyi, improved its ability to mature Hyd-2 (see Fig. 4). Importantly, these truncated variants of $\mathrm{HypC}$ retained their ability to mature Hyd-1 and Hyd-3. This finding also explains why the short (71 amino acids) HypC from D. mccartyi, when heterologously produced in the E. coli hypC-hybG double-null mutant SSH228, showed promiscuous maturation behaviour in that it was able to mature all 3 E. coli enzymes [Hartwig et al., 2015]. A C-terminal extension on the HypC orthologue, HupF, which co-exists with HypC in the cells of the symbiotic nitrogen-fixing bacterium Rhizobium leguminosarum, has been shown to stabilize maturation of the target hydrogenase large subunit towards oxygen [Albareda et al., 2012], suggesting that modification or extension of the
C-terminus can add functional specificity to these chaperones.

The other 2 amino acid regions identified as having significant variability between HypC and HybG [Hartwig et al., 2015] are part of the central OB-fold of the protein, whose main function is to facilitate interaction with HypD and generally with the Hyp-scaffold complex [Drapal and Böck, 1998; Wang et al., 2007]. Both regions, VR1 and VR2, are located on loops that align on the same side of the protein as the C-terminus of HypC in the structure of the HypC-HypD complex from T. kodakarensis [Watanabe et al., 2012]. Notably, the solution structure of E. coli HypC reveals that the C-terminal $\alpha$-helix has an altered orientation (by approx. $90^{\circ}$ ) when it is not in complex with HypD (Fig. 2). However, when in complex with HypD, the C-terminus of HypC realigns and appears more constrained within the HypD fold of the T. kodakarensis complex (Fig. 2c). A further structure of the HypCHypD-HypE complex is available [Watanabe et al., 2012] and shows binding of HypE on the "opposite" side of the conserved regions (Fig. 2c, inset). Based on this ternary structure, it is clear that all 3 variable regions of $\mathrm{HypC}$ are not involved in the interaction with HypD or HypE, which also is in agreement with the fact that HypE has not been shown to interact directly with HypC [Böck et al., 2006] and would be commensurate with VR1, VR2, and VR3 being available for interaction with the large-subunit precursors.

Both the removal of the GS motif, which is absent in HybG, and the introduction of the HQL tripeptide, which is present in $\mathrm{HybG}$, were remarkably well tolerated by HypC with respect to Hyd-3 (HycE) maturation (based on $\mathrm{H}_{2}$ production and enzyme activity). Notably, when the GS motif was introduced into HybG and the HQL removed, the HybG variant showed improved Hyd-3 activity and reduced Hyd-2 activity [Hartwig et al., 2015]. These data indicate that regions VR1 and VR2 are also important in distinguishing $\mathrm{HycE}$ from HybC. Moreover, altering both of these amino acid motifs in HypC reduced Hyd- 1 activity significantly, suggesting that these motifs are important for the recognition of $\mathrm{HyaB}$, the large subunit of Hyd-1; this is also supported by previous findings for HybG [Hartwig et al., 2015]. It is intriguing that, although HybG appears to have a more significant role in maturing HyaB, HypC also seems to be required for maximal Hyd-1 activity during fermentative growth. This might indicate that sub-populations of scaffold complexes containing either HybG or HypC might work together to mature the enzyme, depending on the physiological conditions. It should also be noted that Hyd-1 is a sig-
94

J Mol Microbiol Biotechnol 2018;28:87-97 DOI: $10.1159 / 000489929$
Thomas/Waclawek/Nutschan/Pinske/ Sawers 
Table 2. Strains and plasmids

\begin{tabular}{|c|c|c|}
\hline & Genotype & Reference \\
\hline \multicolumn{3}{|l|}{ Strain } \\
\hline MC4100 & $\begin{array}{l}\mathrm{F}^{-}, \text {araD139, } \Delta(\operatorname{argF}-l a c) U 169, \lambda^{-}, \text {rpsL150, relA1, deoC1, flhD5301, } \\
\Delta(\text { fruK-yeiR }) 725(\text { fruA25 }), r b s R 22, \Delta(\text { fimB-fimE }) 632(:: \mathrm{IS} 1)\end{array}$ & Casadaban [1976] \\
\hline DHP-C & MC4100 $\Delta h y p C$ & Jacobi et al. [1992] \\
\hline DHB-G & MC4100 $\Delta h y b G$ & Blokesch et al. [2001] \\
\hline SHH228 & DHP-C $\Delta h y b G$ & Hartwig et al. [2015] \\
\hline phybGstrep & $h y b G$ in $\mathrm{pASK}-\mathrm{IBA} 3, \mathrm{Amp}^{\mathrm{R}}$ & Soboh et al. [2014] \\
\hline pJA1021 & pACYC184, hypC $C^{+}$from E. coli, Cam $^{\mathrm{R}}$ & Jacobi et al. [1992] \\
\hline pCThypC(+ HQL) & pJA1021, insertion of HQL after amino acid position 16 & our study \\
\hline pCThypC(-GS) & pJA1021, deletion of GS amino acids at position 34 and 35 & our study \\
\hline pCThypC(+ HQL/- GS $)$ & pCThypC(+ HQL), deletion of GS amino acids at 34 and 35 & our study \\
\hline pCThypC(Vstop) & pJA1021, introduction of a stop codon at position 77 & our study \\
\hline pCThypC(G14D) & pJA1021, exchange of $\mathrm{G}$ for $\mathrm{D}$ at amino acid position 14 & our study \\
\hline pCThypC(PAD) & pJA1021, exchange of GQP at amino acid positions $40-43$ for PAD & our study \\
\hline pCThypC(PAD/+ HQL) & pCThypC(PAD), insertion of HQL after amino acid position 16 & our study \\
\hline pCThypC(PAD/+ HQL/Vstop) & pCThypC(PAD/+ HQL), introduction of a stop codon at position 77 & our study \\
\hline pCThypC(PAD/+ HQL/Gstop) & pCThypC(PAD/+ HQL), introduction of a stop codon at position 82 & our study \\
\hline
\end{tabular}

nificantly more abundant enzyme than Hyd-2 during fermentation [Sawers et al., 1985; Sawers and Boxer, 1986].

Only when the truncation of the C-terminal helix in HypC was combined with the changes in VR1 and VR2 could a significant reduction in Hyd-3 activity be observed. This suggests that, as long as the C-terminal extension is present on $\mathrm{HypC}$, HycE can be matured, even if changes are made in VR1 and VR2. The apparent destabilization of the HypC protein by the conversion of the GQP sequence to a PAD sequence (an amino acid sequence found in $\mathrm{HybG}$ ) at the border of the VR2 region was surprising, indicating that not all changes in this region of HypC are tolerated and that they cause severe structural changes.

We could not identify a specific region or amino acid exchange that improved Hyd-1 maturation relative to Hyd-3 activity; however, as was observed for Hyd-3, most amino acid changes were tolerated, such that some active Hyd-1 enzyme was essentially always made. HypC appears to be the general chaperone for Hyd-3 and, depending on the physiological status of the cell, also for Hyd-1 and this is reflected by the fact that it is encoded within the hyp operon in E. coli [Jacobi et al., 1992]. The promiscuity shown by $\mathrm{HyaB}$, the Hyd-1 large subunit, towards $\mathrm{HypC}$ is also in line with the fact that it does not have its own specific HypC-family chaperone encoded within the structural gene operon [Menon et al., 1990]. This is in contrast to HybG, which is encoded within the hyb operon that also encodes the structural components of Hyd2 [Menon et al., 1994]. Nevertheless, the fact that HyaB is also matured by HybG indicates that it is flexible with regard to Hyp-scaffold recognition. The aim of future experiments will be to identify the structural determinants on all 3 of the hydrogenase large-subunit precursors that specify HypC/HybG recognition and interaction.

\section{Experimental Procedures}

\section{Strains and Growth Conditions}

The strains used in this study are listed in Table 2. For routine molecular biology studies, growth was on LB-agar plates or with shaking in LB-broth and at $37^{\circ} \mathrm{C}$ [Miller, 1972]. Anaerobic growths were performed at $37^{\circ} \mathrm{C}$ as standing liquid cultures. Unless stated otherwise, $E$. coli cells were grown in $\mathrm{M} 9$ minimal medium, which included $47.6 \mathrm{mM} \mathrm{Na}_{2} \mathrm{HPO}_{4} \times 2 \mathrm{H}_{2} \mathrm{O}, 22 \mathrm{mM} \mathrm{KH}_{2} \mathrm{PO}_{4}, 8.4 \mathrm{mM}$ $\mathrm{NaCl}, 20 \mathrm{mM} \mathrm{NH}_{4} \mathrm{Cl}, 2 \mathrm{mM} \mathrm{MgSO}_{4}, 0.1 \mathrm{mM} \mathrm{CaCl}_{2}$, and $0.1 \mathrm{~mm}$ thiamin dichloride [Sambrook et al., 1989]. The growth medium was supplemented with trace element solution SLA [Hormann and Andreesen, 1989]. The carbon source was either glucose $(0.8 \%$ $\mathrm{w} / \mathrm{v})$ or glycerol $(0.5 \% \mathrm{w} / \mathrm{v})$ and sodium fumarate $(0.5 \% \mathrm{w} / \mathrm{v})[\mathrm{Saw}-$ ers et al., 1985]. When required, anhydrotetracycline (AHT) was added at a final concentration of $200 \mu \mathrm{g} / \mathrm{mL}$ and added to cultures 
when they had reached an $\mathrm{OD}_{600 \mathrm{~nm}}$ of 0.3 . Cells were harvested when cultures had reached an $\mathrm{OD}_{600 \mathrm{~nm}}$ of between 0.8 and 1.2. When required, the antibiotics ampicillin, kanamycin, or chloramphenicol were added to a final concentration of 100,50 , or 12 $\mu \mathrm{g} / \mathrm{mL}$, respectively. Cells were harvested anaerobically by centrifugation at 5,000 g for $15 \mathrm{~min}$ and at $4^{\circ} \mathrm{C}$. Cell pellets were used immediately or stored at $-20^{\circ} \mathrm{C}$ until use.

\section{Plasmid Construction and Site-Directed Mutagenesis}

Site-directed mutagenesis of the hypC gene was performed using the Quik-Change procedure of Stratagene. The oligonucleotide primers used for mutagenesis are listed in online supplementary Table S1. The authenticity of the mutated hypC genes was validated by DNA sequencing. All plasmids were transformed into the appropriate E. coli strains as described [Chung et al., 1989].

\section{Preparation of Crude Cell Extracts}

E. coli cell paste was re-suspended at a ratio of $1 \mathrm{~g}$ wet weight $/ 3$ $\mathrm{mL}$ in $50 \mathrm{~mm}$ MOPS, pH 7, including $5 \mu \mathrm{g}$ DNase $/ \mathrm{mL}$, and $0.2 \mathrm{mM}$ phenylmethylsulfonyl fluoride. Cells were disrupted anaerobically chamber under an atmosphere of $95 \% \mathrm{~N}_{2}: 5 \% \mathrm{H}_{2}$. Unbroken cells and cell debris were removed by centrifugation for $30 \mathrm{~min}$ at $50,000 \mathrm{~g}$ and $4^{\circ} \mathrm{C}$. The resultant supernatant was termed the crude extract and, unless otherwise stated, was used for all studies reported herein.

Determination of protein concentration was done as described [Lowry et al., 1951].

\section{Non-Denaturing PAGE, Activity-Staining, and \\ Immunoblotting}

Unless otherwise specified, non-denaturing PAGE was performed anaerobically. Separating gels included $0.1 \%(\mathrm{w} / \mathrm{v})$ Triton X-100 as described [Ballantine and Boxer, 1985]. The crude extracts were incubated with a final concentration of $4 \%(\mathrm{w} / \mathrm{v})$ Triton X-100 prior to application (usually $50 \mu \mathrm{g}$ of protein) to the gel, which included $6 \%(\mathrm{w} / \mathrm{v})$ polyacrylamide. Hydrogenase activity-staining was done in $50 \mathrm{~mm}$ MOPS buffer $\mathrm{pH} 7.0$, as described [Sawers et al., 1985], and included $0.5 \mathrm{~mm}$ benzyl viologen (BV) and $1 \mathrm{~mm}$ 2,3,5-triphenyltetrazolium chloride (TTC). Gels were incubated under an atmosphere of $100 \%$ highly pure hydrogen gas. In order to stain specifically for Hyd1 activity, staining was done in a $100 \%$ hydrogen atmosphere using $0.3 \mathrm{~mm}$ phenazine methosulfate (PMS) as mediator and $0.2 \mathrm{mM}$ nitroblue tetrazolium (NBT) as redox dyes [Pinske et al., 2012].

\section{Denaturing PAGE and Immunoblotting}

Polypeptides in crude extracts were separated by $12.5 \%$ (w/v) sodium dodecyl sulfate (SDS)-PAGE [Laemmli, 1970] and gels were either stained with Coomassie Brilliant Blue R or transferred to nitrocellulose membranes [Towbin et al., 1979]. For immunodetection, antibodies directed against HypC were used at a dilution of 1:800. The secondary antibody conjugated to horse-radish peroxidase (Bio-Rad, Munich, Germany) was used according to the manufacturer's instructions. Visualization of the antibody-antigen interaction was achieved using the enhanced chemiluminescence reaction (Agilent Technologies). by sonication ( $30 \mathrm{~W}$ power for $5 \mathrm{~min}$ with 0.5 -s pulses) in a Coy ${ }^{\mathrm{TM}}$

\section{Measurement of Hydrogen Production}

Gas chromatographic determination of hydrogen content in cultures was carried out in Hungate tubes filled with $5 \mathrm{~mL}$ of the respective medium and the $10-\mathrm{mL}$ head space was flushed with nitrogen, as described [Pinske et al., 2015]. An aliquot of $200 \mu \mathrm{L}$ gas phase from the head space was analyzed on a Shimadzu GC2010 Plus gas chromatograph. Pure nitrogen was used as the carrier gas, and the amount of produced hydrogen was calculated based on a standard curve.

\section{Bioinformatic Analyses}

Protein alignment was done using the Muscle algorithm integrated in Jalview [Waterhouse et al., 2009]. Figures of PDB structures were generated using PyMOL (The PyMOL Molecular Graphics System, v1.3, Schrödinger, LLC).

\section{Acknowledgements}

We thank Rica Bremenkamp for expert technical help performing the activity assays. This work was supported by the Deutsche Forschungsgemeinschaft (SA494/3-2).

\section{Disclosure Statement}

The authors declare that they have no competing interests.

\section{Author Contributions}

C.T., M.W., and K.N. carried out the experiments. C.P. designed and prepared figures. R.G.S. and C.P. drafted the manuscript and conceived the study. All authors read and approved the final manuscript.
References
Adams MW, Hall DO: Purification of the membrane-bound hydrogenase of Escherichia coli. Biochem J 1979;183:11-22.

Albareda M, Manyani H, Imperial J, Brito B, Ruiz-Argüeso T, Böck A, Palacios J-M: Dual role of HupF in the biosynthesis of [NiFe] hydrogenase in Rhizobium leguminosarum. BMC Microbiol 2012;12, 256-268.

Albareda M, Pacios LF, Manyani H, Rey L, Brito B, Imperial J, Ruiz-Argüeso T, Palacios JM: Maturation of Rhizobium leguminosarum hydrogenase in the presence of oxygen requires the interaction of the chaperone $\mathrm{HypC}$ and the scaffolding protein HupK. J Biol Chem 2014;289:21217-21229.

Ballantine SP, Boxer DH: Nickel-containing hydrogenase isoenzymes from anaerobically grown Escherichia coli K-12. J Bacteriol 1985; $163 ; 454-459$
Thomas/Waclawek/Nutschan/Pinske/ Sawers 
Blokesch M, Albracht SPJ, Matzanke BF, Drapal NM, Jacobi A, Böck A: The complex between hydrogenase-maturation proteins HypC and HypD is an intermediate in the supply of cyanide to the active site iron of [NiFe]-hydrogenases. J Mol Biol 2004;344:155-167.

Blokesch M, Böck A: Properties of the [NiFe]-hydrogenase maturation protein HypD. FEBS Lett 2006;580:4065-4068.

Blokesch M, Magalon A, Böck A: Interplay between the specific chaperone-like proteins HybG and HypC in maturation of hydrogenases 1, 2, and 3 from Escherichia coli. J Bacteriol 2001;183:2817-2822.

Böck A, King P, Blokesch M, Posewitz M: Maturation of hydrogenases. Adv Microb Physiol 2006;51:1-71.

Bürstel I, Siebert E, Winter G, Hummel P, Zebger I, Friedrich B, Lenz O: A universal scaffold for synthesis of the $\mathrm{Fe}(\mathrm{CN})_{2}(\mathrm{CO})$ moiety of [NiFe] hydrogenase. J Biol Chem 2012;287: 38845-38853.

Casadaban MJ: Transposition and fusion of the lac genes to selected promoters in Escherichia coli using bacteriophage lambda and $\mathrm{Mu}$. J Mol Biol 1976;104:541-555.

Chung CT, Niemela SL, Miller RH: One-step preparation of competent Escherichia coli: transformation and storage of bacterial cells in the same solution. Proc Natl Acad Sci USA 1989;86:2172-2175.

Drapal N, Böck A: Interaction of the hydrogenase accessory protein $\mathrm{HypC}$ with $\mathrm{HycE}$, the large subunit of Escherichia coli hydrogenase 3 during enzyme maturation. Biochemistry 1998; 37:2941-2948.

Hartwig S, Thomas C, Krumova N, Quitzke V, Türkowsky D, Jehmlich N, Adrian L, Sawers RG: Heterologous complementation studies in Escherichia coli with the Hyp accessory protein machinery from Chloroflexi provide insight into [NiFe]-hydrogenase large subunit recognition by the HypC protein family. Microbiology 2015;161:2204-2219.

Hormann K, Andreesen JR: Reductive cleavage of sarcosine and betaine by Eubaterium acidaminophilum via enzyme systems different from glycine reductase. Arch Microbiol 1989;153: 50-59.

Jacobi A, Rossmann R, Böck A: The hyp operon gene products are required for the maturation of catalytically active hydrogenase isoenzymes in Escherichia coli. Arch Microbiol 1992;158:444-451.

Jones AK, Lenz O, Strack A, Buhrke T, Friedrich $\mathrm{B}$ : NiFe hydrogenase active site biosynthesis: identification of Hyp protein complexes in Ralstonia eutropha. Biochemistry 2004;43: 13467-13477.

Lacasse MJ, Zamble DB: [NiFe]-hydrogenase maturation. Biochemistry 2016;55:16891701.

Laemmli UK: Cleavage of structural proteins during the assembly of the head of bacteriophage T4. Nature 1970;227:680-685.
Lowry O, Rosebrough N, Farr A, Randall R: Protein measurement with the Folin phenol reagent. J Biol Chem 1951;193:265-275.

Magalon A, Böck A: Analysis of the HypC-HycE complex, a key intermediate in the assembly of the metal center of the Escherichia coli hydrogenase 3. J Biol Chem 2000;275:2111421120.

Menon NK, Chatelus CY, Der Vartanian M, Wendt JC, Shanmugam KT, Peck HD Jr, Przybyla AE: Cloning, sequencing, and mutational analysis of the $h y b$ operon encoding Escherichia coli hydrogenase 2. J Bacteriol 1994;176:4416-4423.

Menon NK, Robbins J, Peck HD Jr, Chatelus CY, Choi ES, Przybyla AE: Cloning and sequencing of a putative Escherichia coli [NiFe]-hydrogenase-1 operon containing six open reading frames. J Bacteriol 1990;172:19691977.

Miller JH (ed): Experiments in Molecular Genetics. New York, Cold Spring Harbor Laboratory, 1972.

Penfold DW, Sargent F, Macaskie LE: Inactivation of the Escherichia coli K-12 twin-arginine translocation system promoters increased hydrogen production. FEMS Microbiol Lett 2006;262:135-137.

Pinske C, Jaroschinsky M, Linek S, Kelly CL, Sargent F, Sawers RG: Physiology and bioenergetics of [NiFe]-hydrogenase 2-catalyzed $\mathrm{H}_{2}$ consuming and $\mathrm{H}_{2}$-producing reactions in Escherichia coli. J Bacteriol 2015;197:296306.

Pinske C, Jaroschinsky M, Sargent F, Sawers RG: Zymographic differentiation of [NiFe]-hydrogenases 1, 2 and 3 of Escherichia coli K-12. BMC Microbiol 2012;12:134.

Pinske C, Sawers RG: Anaerobic formate and hydrogen metabolism EcoSal Plus 2016, DOI: 10.1128/ecosalplus.ESP-0011-2016.

Sambrook J, Fritsch EF, Maniatis T (eds): Molecular Cloning: A Laboratory Manual. New York, Cold Spring Harbor Laboratory, New York, 1989.

Sargent F: The model [NiFe]-hydrogenases of Escherichia coli. Adv Microb Physiol 2016;68: 433-507.

Sawers RG, Ballantine SP, Boxer DH: Differential expression of hydrogenase isoenzymes in Escherichia coli K-12: evidence for a third isoenzyme. J Bacteriol 1985;164:1324-1331.

Sawers RG, Boxer DH: Purification and properties of membrane-bound hydrogenase isoenzyme 1 from anaerobically grown Escherichia coli K-12. Eur J Biochem 1986;156:265-275.

Senger M, Stripp ST, Soboh B: Proteolytic cleavage orchestrates cofactor insertion and protein assembly in [NiFe]-hydrogenase biosynthesis. J Biol Chem 2017;292:11670-11681.
Soboh B, Lindenstrauss U, Granich C, Javed M, Herzberg M, Thomas C, Stripp, ST: [NiFe]hydrogenase maturation in vitro: analysis of the roles of the HybG and HypD accessory proteins. Biochem J 2014;464:169-177.

Soboh B, Pinske C, Kuhns M, Waclawek M, Ihling C, Trchounian K, Trchounian A, Sinz A, Sawers RG: The respiratory molybdo-selenoprotein formate dehydrogenases of Escherichia coli have hydrogen: benzyl viologen oxidoreductase activity. BMC Microbiol 2011;11:173.

Soboh B, Stripp ST, Bielak C, Lindenstrauß U, Braussemann M, Javaid M, Hallensleben $M$, Granich C, Herzberg M, Heberle J, Sawers RG: The [NiFe]-hydrogenase accessory chaperones HypC and HybG of Escherichia coli are iron- and carbon dioxide-binding proteins. FEBS Lett 2013;587:2512-2516.

Soboh B, Stripp S, Muhr E, Granich C, Braussemann M, Herzberg M, Heberle J, Sawers RG: [NiFe]-hydrogenase maturation: isolation of a HypC-HypD complex carrying diatomic $\mathrm{CO}$ and $\mathrm{CN}^{-}$ligands. FEBS Lett 2012;586: 3882-3887.

Stripp ST, Soboh B, Lindenstrauss U, Braussemann M, Herzberg M, Nies DH, Sawers RG, Heberle J: HypD is the scaffold protein for $\mathrm{Fe}-$ $(\mathrm{CN})_{2} \mathrm{CO}$ cofactor assembly in $[\mathrm{NiFe}]-\mathrm{hy}-$ drogenase maturation. Biochemistry 2013;52: 3289-3296.

Towbin H, Staehelin T, Gordon J: Electrophoretic transfer of proteins from polyacrylamide gels to nitrocellulose sheets: procedure and some applications. Proc Natl Acad Sci USA 1979;76:4350-4354.

Vignais PM, Billoud B: Occurrence, classification, and biological function of hydrogenases: an overview. Chem Rev 2007;107:4206-4272.

Wang L, Xia B, Jin C: Solution structure of Escherichia coli HypC. Bichem Biophy Res Commun 2007;361:665-669.

Watanabe S, Matsumi R, Atomi H, Imanaka T, Miki K: Crystal structures of the HypCD complex and the HypCDE ternary complex: transient intermediate complexes during [NiFe] hydrogenase maturation. Structure 2012;20: $1-14$.

Waterhouse AM, Procter JB, Martin DM, Clamp $\mathrm{M}$, Barton GJ: Jalview version 2 - a multiple sequence alignment editor and analysis workbench. Bioinformatics 2009;25:1189-1191.

Winter G, Buhrke T, Lenz O, Jones AK, Forgber M, Friedrich B: A model system for [NiFe] hydrogenase maturation studies: purification of an active site-containing hydrogenase large subunit without small subunit. FEBS Lett 2005;579:4292-4296.

Wolf I, Burke T, Dernedde J, Pohlmann A, Friedrich B: Duplication of hyp genes involved in maturation of [NiFe] hydrogenases in Alcaligenes eutrophus H16. Arch Microbiol 1998; 170:451-459.
HypC Recognition of Hydrogenase

Apo-Large Subunits
J Mol Microbiol Biotechnol 2018;28:87-97 DOI: $10.1159 / 000489929$ 